\title{
Safety and Efficacy of Same-Session Bilateral Ureteroscopy
}

\author{
BRENT K. HOLLENBECK, M.D., TIMOTHY G. SCHUSTER, M.D., GARY J. FAERBER, M.D., \\ and J. STUART WOLF, JR., M.D.
}

\begin{abstract}
Purpose: Same-session ureteroscopy for bilateral urinary calculi would potentially reduce costs and the need for a second anesthetic compared with staged procedures. We sought to establish the safety and efficacy of same-session bilateral ureteroscopy relative to procedures for staged bilateral and multiple unilateral calculi in the context of contemporary instrumentation.

Patients and Methods: A series of 626 consecutive patients underwent ureteroscopy for calculi between January 1997 and August 2001. Among these, 34 patients with bilateral calculi (11 staged and 23 treated in one sitting) and 54 patients with multiple unilateral calculi in distinct locations were included in this study. Multivariable regression was used to determine the association of patient-specific and technical factors with postoperative morbidity.

Results: Stone-free rates were similar in the two groups and ranged from $50 \%$ to $100 \%$ depending on stone location. Postoperative complications occurred in $6(11 \%)$ and $3(14 \%)$ of the patients treated for multiple unilateral and for bilateral calculi in a staged procedure, respectively, compared with 7 (29\%) of those undergoing same-session bilateral ureteroscopy $(P=\mathbf{0 . 1 2})$. Logistic regression revealed that same-session bilateral ureteroscopy (odds ratio $[\mathrm{OR}] 4.0 ; P=0.02)$ and absence of a postoperative stent $(\mathrm{OR} 1.7 ; P=0.03)$ were associated with added morbidity. However, the cumulative risk of performing staged bilateral procedures (14\% per procedure) approximated that of bilateral ureteroscopy in one sitting (29\%).

Conclusion: Bilateral ureteroscopy carries an increased risk of postoperative morbidity. The risk is proportional to the number of renal units treated and may be assumed at once (e.g., same-session) or over time (e.g., staged) as it applies to patients requiring bilateral ureteroscopy.
\end{abstract}

\section{INTRODUCTION}

A DVANCEMENTS IN FIBEROPTICS over the past decade have led to the miniaturization of the ureteroscope, thereby facilitating the treatment of urinary calculi. Clinical manifestations of these refinements have been improvements in treatment success and patient morbidity. ${ }^{1,2}$ The technique continues to evolve as investigators seek to optimize stone-free rates while minimizing potentially untoward features of the treatment itself (e.g., ureteral stents). ${ }^{3}$

The advantages of same-session bilateral ureteroscopy compared with staged procedures might include a reduction in overall operative time and anesthetic requirements and minimization of the duration of convalescence. Conversely, the technique would expose both ureters to injury that could lead to significant morbidity. Two series of patients treated with same- session bilateral ureteroscopy for calculous disease have been reported. These series were composed largely of patients with small, distal ureteral calculi treated with larger $(11 \mathrm{~F}-12 \mathrm{~F})$ ureteroscopes and were characterized by high rates of intraoperative ureteral injury (as high as $22 \%$ ) and postoperative fever $(4 \%-13 \%) .{ }^{4,5}$ We sought to demonstrate the safety and efficacy of bilateral ureteroscopy utilizing contemporary instrumentation for calculi located throughout the upper urinary tract.

\section{PATIENTS AND METHODS}

\section{Patients}

Six hundred twenty-six consecutive patients underwent ureteroscopy for urinary calculous disease between January 1 , 1997, and August 31, 2001, at the University of Michigan. Of

Department of Urology, University of Michigan, Ann Arbor, Michigan. 
this series, 23 patients (46 renal units) underwent 24 samesession bilateral ureteroscopic treatments and comprise our study population (Table 1). The single patient who required a second procedure had large, impacted calculi bilaterally mandating stent placement without treatment after the first attempt. The primary endpoint of the study was the overall complication rate.

To provide a context for these results, we also examined the outcomes for those patients $(\mathrm{N}=54)$ treated for multiple calculi within one renal unit and those $(\mathrm{N}=11)$ treated with staged ureteroscopy (within 2 months) for bilateral urolithiasis. The former group was expected to have similar stone burdens (the sum of the largest lengths for all calculi) and operative time, thus providing a basis for assessing the effects of the bilateral procedure. The criterion for inclusion in this group was that the calculi must be located in two separate positions within the kidney (e.g., upper, middle, or lower calix; renal pelvis) and/or ureter (e.g., lower or upper) and not be merely a collection of stones in one locale (e.g., lower pole only). The latter cohort was comprised of patients who would have been candidates for a same-session bilateral procedure but were treated in separate sittings because of surgeon preference. This group was intended to provide insight into the effects of staging. Because this was a retrospective study, we were unable to define with certainty how many of the staged procedures started out as intended same-session procedures. However, this undoubtedly occurred on a few occasions. We generally approached the most symptomatic side first or, if there was no difference, the side that was obstructed or had the largest stone burden. Of the three most experienced surgeons, one tended to opt for same-session treatment in lieu of a staged procedure when treating bilateral stones $(80 \%$ v $42 \%$ v $40 \% ; P=0.08)$.

\section{Techniques}

Ureteroscopy was generally performed with either a $6.9 \mathrm{~F}$ semirigid or flexible ureteroscope, although a $7.5 \mathrm{~F}$ flexible ureteroscope was used occasionally. Ureteral dilation, when necessary, was carried out to $15 \mathrm{~F}$ using a balloon dilator. A ureteral access sheath was not typically used, and irrigation was under pressure (150-300 $\mathrm{mm} \mathrm{Hg}$ ) and controlled via a valve attached to the ureteroscope. Ureteral stents were placed following long (>90 minutes) or traumatic procedures. ${ }^{6}$ The holmium laser (200- or 300- $\mu \mathrm{m}$ fiber) was used to fragment the offending calculus into 1 - to $2-\mathrm{mm}$ pieces in most cases requiring lithotripsy.

Procedures were considered successful if either a solitary calculus was removed in its entirety or all fragments were absent on radiographic follow-up. All patients who underwent lithotripsy required radiographic follow-up for their procedure to be considered a success, and when possible, stone-free rates reflect imaging obtained at least 1 month after their procedure to allow for fragment passage. Radiographic follow-up typically consisted of a plain radiograph at 1 month and subsequent intervals thereafter, depending on the patient's stone status.

\section{Statistical methods}

Bivariate analyses were performed on all clinical data and outcome measures. The chi-square test was utilized to determine the significance of differences of nominal data between the two groups. The Kurskal-Wallis test was used to assess the significance regarding continuous data. Between-group comparisons of patient, stone, and operative data were not performed; rather, all potentially relevant variables $(P<0.3)$ were included in initial multivariable models. Comparisons of postoperative morbidity were made using the following groupings: (1) bilateral (staged or simultaneous) $v$ only unilateral procedure; and (2) same-session bilateral $v$ unilateral (staged bilateral and multiple unilateral) procedure. Logistic regression ${ }^{7}$ was performed on the entire sample (same-session bilateral, staged bilateral, and unilateral) in a retrograde fashion to assess the association of clinical and operative data with postoperative morbidity. All analyses were conducted using Statview (SAS Institute, Cary, NC) and were performed at the 5\% significance level.

Table 1. Patient and Stone Characteristics

\begin{tabular}{|c|c|c|c|c|}
\hline & $\begin{array}{c}\text { Unilateral } \\
\text { (54 renal units) }\end{array}$ & $\begin{array}{l}\text { Same-session bilateral } \\
\quad(23 \text { renal units })\end{array}$ & $\begin{array}{l}\text { Staged bilateral } \\
(22 \text { renal units })\end{array}$ & $\mathrm{p}$ value \\
\hline Age (years) & $51.1 \pm 15.7$ & $52.0 \pm 14.9$ & $42.4 \pm 9.3$ & 0.03 \\
\hline Total stone burden (mm) & $16.4 \pm 7.1$ & $16.1 \pm 11.7$ & $7.0 \pm 4.2$ & $<0.0001$ \\
\hline No. stones treated & $2.1 \pm 0.3$ & $2.0 \pm 0.6$ & $1.1 \pm 0.5$ & $<0.0001$ \\
\hline \multicolumn{5}{|l|}{ Location of calculi (\%) } \\
\hline Upper calix & $12(22.2)$ & $4(17.4)$ & $3(13.6)$ & 0.65 \\
\hline Middle calix & $12(22.2)$ & $2(8.7)$ & $3(13.6)$ & 0.29 \\
\hline Lower calix & $39(72.2)$ & $9(39.1)$ & $5(22.7)$ & 0.005 \\
\hline Renal pelvis & $12(22.2)$ & $14(61.0)$ & $5(22.7)$ & 0.004 \\
\hline Proximal ureter & $15(27.8)$ & $2(8.7)$ & $2(9.1)$ & 0.05 \\
\hline Middle ureter & $10(18.5)$ & $2(8.7)$ & $6(27.3)$ & 0.25 \\
\hline Distal ureter & $12(22.2)$ & $7(30.4)$ & $2(9.1)$ & 0.24 \\
\hline Distribution of calculi (\%) & & & & $<0.0001$ \\
\hline Renal only & $21(38.9)$ & $15(65.2)$ & $12(54.5)$ & \\
\hline Renal and ureteral & $31(57.4)$ & $4(17.4)$ & - & \\
\hline Ureteral only & $2(3.7)$ & $4(17.4)$ & $10(45.5)$ & \\
\hline Prior instrumentation (\%) & $30(55.6)$ & $12(52.2)$ & $18(81.8)$ & 0.05 \\
\hline Follow-up (mos.) & $3.6 \pm 3.6$ & $2.3 \pm 3.9$ & $3.3 \pm 4.9$ & 0.06 \\
\hline
\end{tabular}


Table 2. Operative Data and Outcome Measures (\%)

\begin{tabular}{|c|c|c|c|c|}
\hline & $\begin{array}{c}\text { Unilateral } \\
(54 \text { procedures })^{\natural}\end{array}$ & $\begin{array}{l}\text { Same-session bilateral } \\
\quad(24 \text { procedures })^{\mathrm{a}}\end{array}$ & $\begin{array}{l}\text { Staged bilateral } \\
(22 \text { procedures })^{\natural}\end{array}$ & $\mathrm{p}$ value \\
\hline Operative time (min) & $74 \pm 35$ & $90 \pm 46$ & $68 \pm 34$ & 0.19 \\
\hline Preoperative stent & $18(33)$ & $5(20)$ & $7(32)$ & 0.53 \\
\hline Rigid ureteroscopy & $10(18)$ & $5(20)$ & $4(18)$ & 0.97 \\
\hline Flexible ureteroscopy & $53(98)$ & $21(87)$ & $19(86)$ & 0.09 \\
\hline Lithotripsy & $43(79)$ & $17(70)$ & $16(73)$ & 0.65 \\
\hline General anesthesia & $33(61)$ & $18(75)$ & $12(55)$ & 0.32 \\
\hline Ureteral dilation & $10(18)$ & $6(25)$ & $2(9)$ & 0.37 \\
\hline Postoperative stent & $34(63)$ & $18(75)$ & $13(59)$ & 0.47 \\
\hline Intraoperative complication & - & $1(4)$ & $1(5)$ & 0.30 \\
\hline Postoperative complication & $6(11)$ & $7(29)$ & $3(14)$ & 0.12 \\
\hline Stone free & $27 / 45(60)^{b}$ & $11 / 21(52)^{\mathrm{c}}$ & $15 / 19(79)^{\mathrm{d}}$ & 0.25 \\
\hline Stone free with 1 month-follow-up & $27 / 37(73)^{e}$ & $11 / 15(73)^{\mathrm{f}}$ & $15 / 19(79)^{d}$ & 0.88 \\
\hline
\end{tabular}

${ }^{\mathrm{a}}$ Except where indicated.

${ }^{\mathrm{b}}$ Available on $45 / 54(83 \%)$ of procedures.

${ }^{c}$ Available on $21 / 24(88 \%)$ of procedures.

d Available on 15/22 (68\%) of procedures.

eAvailable on 37/54 (69\%) of procedures.

${ }^{\mathrm{f}}$ Available on $15 / 24(63 \%)$ of procedures.

\section{RESULTS}

Patients treated with staged bilateral procedures had significantly fewer calculi $(\mathrm{N}=1.1)$ than those with unilateral $(\mathrm{N}=$ $2.1)$ calculi or treated in same-session bilateral $(\mathrm{N}=2.0)$ procedures $(P<0.0001)$. This difference is subsequently manifested as a smaller stone burden treated in the staged bilateral group $(P<0.0001)$.

There were no differences in any of the technical aspects or stone-free rates (among those with adequate follow-up) between the three groups (Table 2). Stone-free rates are further stratified by stone location in Table 3. Patients treated for strictly ureteral calculi were entirely stone free after 1 month regardless of whether the procedure was bilateral or unilateral (although the sample size was small).

There were two intraoperative complications, one in the staged bilateral and one in the same-session bilateral group, which consisted of small ureteral perforations managed with a ureteral stent following the procedures. Postoperative complications are described in Table 3. Postoperative "pain" was the most frequent complication, mandating a readmission, emergency department visit, or reinstrumentation in $17 \%$ of patients in the same-session bilateral group, $9 \%$ of the staged bilateral group, and $7 \%$ of the unilateral group. One patient treated for multiple unilateral calculi had severe flank pain resulting in early removal of her ureteral stent. No other patient required reinstrumentation. Of note, one patient treated for large bilateral calculi in one session sustained a pulmonary embolus resulting in his death. His procedure lasted 175 minutes, although the first side was completed in less than 1 hour.

Patients undergoing same-session bilateral ureteroscopy had a significantly higher postoperativecomplication rate than those undergoing unilateral (multiple unilateral and staged bilateral) procedures $(29 \% v 12 \% ; P=0.04)$ (Table 4). Conversely, when grouping all bilateral (staged and same-session) patients together, there was no greater risk of postoperative morbidity than in patients treated only unilaterally $(22 \% v 11 \% ; P=0.15)$. We also noted no difference when comparing the complication rates of each group separately $(P=0.12)$. Among the same-session bilateral cohort, 4 patients $(16 \%)$ had postoperative complications attributed to pain. This effect was unrelated to ureteral stenting, as two patients had no stent, one patient had a unilateral stent, and one patient had bilateral stents $(P=0.14)$.

Logistic regression analysis was performed on the entire

Table 3. Stone-Free Rates as Function of Stone Location (\%)

\begin{tabular}{lccc}
\hline & $\begin{array}{c}\text { Unilateral } \\
(45 \text { patients })\end{array}$ & $\begin{array}{c}\text { Same-session bilateral } \\
(21 \text { patients })\end{array}$ & $\begin{array}{c}\text { Staged bilateral } \\
(7 \text { patients })\end{array}$ \\
\hline Overall stone free & & & $2 / 4(50)$ \\
$\quad$ Renal only & $9 / 17(53)$ & $5 / 12(42)$ & - \\
Renal and ureteral & $17 / 27(63)$ & $2 / 4(50)$ & $3 / 3(100)$ \\
Ureteral only & $1 / 1(100)$ & $4 / 5(80)$ & $2 / 4(50)$ \\
$>$ 1-month follow-up & $9 / 15(60)$ & $5 / 8(63)$ & - \\
Renal only & $17 / 21(81)$ & $2 / 3(67)$ & $3 / 3(100)$ \\
Renal and ureteral & $1 / 1(100)$ & $4 / 4(100)$ & \\
Ureteral only & &
\end{tabular}


Table 4. Intraoperative and Postoperative Complications (\%)

\begin{tabular}{lccc}
\hline & $\begin{array}{c}\text { Unilateral } \\
\text { (54 procedures) }\end{array}$ & $\begin{array}{c}\text { Same-session bilateral } \\
\text { (24 procedures) }\end{array}$ & $\begin{array}{c}\text { Staged bilateral } \\
(22 \text { procedures) }\end{array}$ \\
\hline Pain & & $2(8)$ & - \\
$\quad$ ER visit & $3(6)$ & $2(8)$ & - \\
$\quad$ Readmission & $1(2)$ & - & - \\
$\quad$ Stent removal & $1(2)$ & $1(4)$ & - \\
Perinephric hematoma & $1(2)$ & $1(4)$ & - \\
UTI/urosepsis & - & $1(4)$ & $3(14)$ \\
PE/death & $-(11)$ & $7(29)^{\mathrm{a}}$ & - \\
Urinoma & $6(1)$ & - \\
Total & & & - \\
\hline
\end{tabular}

sample (including unilateral, staged bilateral, and same-session bilateral patients) to assess the independent association of the various clinical and technical features with the development of a postoperativecomplication. Patients undergoing same-session bilateral ureteroscopy (OR 4.0; $P=0.02$ ) and those managed without a postoperative stent (OR $1.7 ; P=0.03$ ) were more likely to develop a postoperative complication.

\section{DISCUSSION}

Opponents of same-session bilateral ureteroscopy cite potential injury to both ureters as a rationale for performing treatment of these calculi in separate sittings. Anecdotal reports of same-session bilateral ureteroscopy utilized larger $(10.5 \mathrm{~F}-11 \mathrm{~F})$ ureteroscopes ${ }^{4,5}$ and were characterized by high ureteral perforation rates (up to 22\%) and frequent postoperative fever $(4 \%-13 \%)$. Most of the calculi treated were located in the distal ureter, and, although no long-term postoperative complications were noted, a greater frequency of significant ureteral perforations and ureteral strictures has been reported in larger series utilizing similar-size ureteroscopes. ${ }^{8,9}$

Given these reports and the documented improvements in stone-free and complication rates of ureteroscopy ${ }^{1,2,10}$ largely attributed to advancements in instrumentation, we sought to demonstrate the safety of bilateral ureteroscopy for urinary calculi located throughout the urinary tract. Specifically, the emphasis of the current study was to justify the use of bilateral ureteroscopy by focusing on morbidity (the primary endpoint of this study) rather than efficacy (a secondary endpoint). For comparison, we used two controls: patients treated for multiple unilateral calculi in at least two distinct locations (as these individuals would likely possess similar stone burdens and require similar technical considerations, thereby providing a context to interpret the effects of instrumenting both ureters as opposed to one) and patients treated for bilateral calculi in a separate sitting (as these individuals would provide a context for evaluation of a staged versus a simultaneous approach).

The seminal finding of our study was the tendency toward more frequent postoperative complications among those patients treated for bilateral calculi in a single sitting compared with those treated unilaterally or bilaterally in a staged procedure. This finding did not reach statistical significance on bivariate analysis because of inadequate statistical power. How- ever, our $11 \%$ and $14 \%$ postoperative complication rates (with no major complications) among patients treated for unilateral and bilateral (staged) calculi are comparable to the rates in other contemporary series $(10 \%-12 \%),{ }^{1,11,12}$ thereby providing a valid context in which to interpret our results in treating bilateral stones in the same sitting. After adjusting for differences among the three groups in our multivariable analysis, we determined that patients undergoing same-session bilateral ureteroscopy were four times as likely to develop a postoperative complication as patients treated either unilaterally or with staged bilateral procedures. At first glance, this added risk of performing same-session bilateral ureteroscopy might argue for staging the procedure; however, our complication rate of $29 \%$ for same-session patients is equivalent to a $14.5 \%$ rate per renal unit, which is similar to our reported rates for patients with multiple unilateralcalculi and those with bilateral calculi treated in two sessions. This implies that the overall risk of treating a patient with bilateral stones is determined by the number of renal units addressed independent of whether they are treated simultaneously or in separate procedures and that by staging the treatment, the risk of developing a complication is only diffused over time rather than being assumed collectively at the time of a same-session bilateral procedure.

The results from the current study also suggest the need for postoperative ureteral stents in those treated for bilateral or multiple unilateral calculi, as these patients were $70 \%$ more likely to develop a postoperative complication when a ureteral stent was not placed after their procedure. Other investigators have demonstrated that ureteral stents are not needed after treatment of uncomplicated distal ureteral calculi. ${ }^{13}$ This proposition, although at odds with current practice trends based on animal data, ${ }^{14,15}$ was confirmed by a multi-institutional randomized trial. ${ }^{3} \mathrm{Al}$ though we advocate "stentless" ureteroscopy for calculi throughout the urinary tract in selected patients, ${ }^{6}$ the current study enables us to refine this evolving philosophy. Patients in this report generally had larger calculi treated in multiple locations and consequently had longer operations (79 $v 46$ minutes) than the unstented population in a prior study. ${ }^{6}$ These findings reiterate the need to develop criteria for forgoing stents based on large institutional series that can subsequently be tested in a randomized setting. On the basis of our findings, we now place at least a unilateral ureteral stent in patients undergoing bilateral ureteroscopy and are more likely to use a stent when treating multiple unilateral calculi in at least two distinct locations. 
The principal limitations of this study are that it is retrospective and there is no long-term postoperative imaging. As a tertiary referral center, we often provide definitive treatment; however, after an initial postoperative visit (usually with radiographic imaging), patients return to the care of their local physicians. Consequently, patient follow-up is often short, and the success rates presenetd likely underestimate the true stonefree rates that are achieved after sufficient time has elapsed for fragment passage. However, this limitation should be placed in perspective, as assessing patient morbidity after bilateral ureteroscopy, rather than defining therapeutic efficacy, was the primary goal of the study. Another potential limitation is the small number of patients treated with staged bilateral procedures. Nonetheless, our findings suggest that same-session bilateral ureteroscopy is associated with a greater risk of a postoperative complication compared with unilateral treatment. However, patients who require a second treatment (such as those with bilateral calculi who are treated in separate sittings) assume the risk of the second procedure, which, in conjunction with that of the first procedure, approximates the risk of treating bilateral calculi in a single session.

\section{CONCLUSION}

In general, same-session bilateral ureteroscopy carries with it an inherently higher risk of postoperative morbidity compared with unilateral procedures. This risk appears to be independent of various clinical and stone features. Because the risk among these patients is twice that for those treated with staged procedures, the overall chance of developing a postoperative complication is essentially equivalent. Ureteral stenting of patients with multiple unilateral (in two distinct locations) and bilateral calculi appears to lessen the risk of a postoperative complication.

\section{REFERENCES}

1. Harmon WJ, Sershon PD, Blute ML, et al. Ureteroscopy: Current practice and long-term complications. J Urol 1997;157:28.
2. Hollenbeck BK, Schuster TG, Faerber GJ, et al. Comparison of outcomes of ureteroscopy for ureteral calculi located above and below the pelvic brim. Urology 2001;58:351.

3. Borboroglu PG, Amling CL, Schenkman NS, et al. Ureteral stenting after ureteroscopy for distal ureteral calculi: A multi-institutional prospective randomized controlled study assessing pain, outcomes and complications. J Urol 2001;166:1651.

4. Deliveliotis CH, Picramenos D, Alexopoulo K, et al. One-session bilateral ureteroscopy: Is it safe in selected patients. Int Urol Nephrol 1996;28:481.

5. Camilleri JC, Schwalb DM, Eshghi M. Bilateral same session ureteroscopy. J Urol 1994;152:49.

6. Hollenbeck BK, Schuster TG, Faerber GJ, et al. Routine placement of ureteral stents is unnecessary following ureteroscopy for urinary calculi. Urology 2001;57:639.

7. Hosmer DW Jr, Lemeshow S. Applied Logistic Regression. New York: John Wiley and Sons, 1989.

8. Netto NR Jr, Claro DA, Esteves SC, et al. Ureteroscopic stone removal in the distal ureter: Why change? J Urol 1997;157:2081.

9. Stoller ML, Wolf JS Jr, Hofman R, et al. Ureteroscopy without routine balloon dilation: An outcome assessment. J Urol 1992; 147:1238.

10. Blute ML, Segura JW, Patterson DE. Ureteroscopy. J Urol 1988; 139:510.

11. Cheung MC, Lee F, Leung YL, et al. Outpatient ureteroscopy: Predictive factors for postoperative events. Urology 2001;58:914.

12. Tawfiek ER, Bagley DH. Management of upper urinary tract calculi with ureteroscopic techniques. Urology 1999;53:25.

13. Hosking DH, McColm SE, Smith WE. Is stenting following ureteroscopy for removal of distal ureteral calculi necessary. J Urol 1999;161:48.

14. Boddy SA, Nimmon CC, Jones S, et al. Acute ureteric dilatation for ureteroscopy: An experimental study. Br J Urol 1988;61:27.

15. Lindell O, Makinen J, Salo J, et al. Intramural ureteric injury due to acute dilation. Ann Chir Gynaecol 1991;80:402.

Address reprint requests to: J. Stuart Wolf, Jr., M.D. 1500 E. Medical Center Drive

TC $2916 \mathrm{H}$

Ann Arbor, MI 48109-0330

E-mail: Wolfs@umich.edu 


\section{This article has been cited by:}

1. Barry M. Mason , Philip T. Koi , Jason Hafron , Paul Milhoua, David M. Hoenig . 2008. Safety and Efficacy of Synchronous Percutaneous Nephrostolithotomy and Contralateral Ureterorenoscopy for Bilateral CalculiSafety and Efficacy of Synchronous Percutaneous Nephrostolithotomy and Contralateral Ureterorenoscopy for Bilateral Calculi. Journal of Endourology 22:5, 889-894. [Abstract] [PDF] [PDF Plus]

2.Zafer Gökhan Gürbüz , Şaban Mimaroǧlu , Levent Gürkan , Mehmet Öder , Levent Verim . 2006. Ureteroscopic Treatment of Multiple Distal-Ureteral StonesUreteroscopic Treatment of Multiple Distal-Ureteral Stones. Journal of Endourology 20:12, 1022-1024. [Abstract] [PDF] [PDF Plus]

3. Steve Y. Chung, Chris H. Chon, Christopher S. Ng, Gerhard J. Fuchs . 2006. Simultaneous Bilateral Retrograde Intrarenal Surgery for Stone Disease in Patients with Significant ComorbiditiesSimultaneous Bilateral Retrograde Intrarenal Surgery for Stone Disease in Patients with Significant Comorbidities. Journal of Endourology 20:10, 761-765. [Abstract] [PDF] [PDF Plus] 